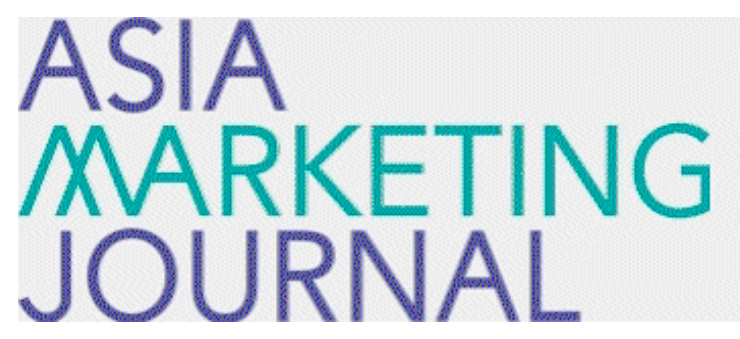

ASIA MARKETING JOURNAL

Volume 11 | Issue 2

Article 1

7-30-2009

\title{
Marketing Feng Shui to Asia
}

\section{Bela Florenthal}

Noriko Yagi

Hong Jiang Xu

Follow this and additional works at: https://amj.kma.re.kr/journal

Part of the Marketing Commons

\section{Recommended Citation}

Florenthal, Bela; Yagi, Noriko; and Xu, Hong Jiang (2009) "Marketing Feng Shui to Asia," Asia Marketing Journal: Vol. 11 : Iss. 2 , Article 1.

Available at: https://doi.org/10.53728/2765-6500.1233

This Article is brought to you for free and open access by Asia Marketing Journal. It has been accepted for inclusion in Asia Marketing Journal by an authorized editor of Asia Marketing Journal. 


\title{
Marketing Feng Shui to Asia: A Case Study
}

\author{
Bela Florenthal* \\ Noriko Yagi** \\ Hongjiang $\mathrm{Xu}^{* * * *}$
}

Feng Shui practice is very popular in East Asia and has been rapidly adopted by the population of the West. As Feng Shui involves knowledge of object placement, it opens opportunities to market Feng Shui knowledge and products. This paper presents an analysis of a successful Feng Shui enterprise, World of Feng Shui (WOFS), that has been established by a well-known Feng Shui expert Lillian Too and her daughter Jennifer Too. The enterprise's marketing strategies and tactics are tied to the theoretical concept of social influence, widely researched in the consumer behavior literature. The three types of social influence (informational, utilitarian, and value-expressive) are examined in relation to WOFS' marketing strategies using secondary data material. The main results indicate that the strategies of WOFS enterprise address all three types of social influence. The articles generated onand off-line can be mostly associated with the informational influence. The off- line activities such as events, courses/workshops, and TV shows are also informational in nature. The Q \& A sections/ postings can be considered as representative of the utilitarian influence. They give experts (e.g., Lillian Too) the opportunity to provide individuals with problem-specific recommendations. Mega-mall website provides the value-expressive influence as purchase and consumption of the Feng Shui products is most susceptible to this type of influence. In terms of implications, WOFS enterprise strategies are suitable not only for consumes but also for business executives in Asia and in the West as architects, designers, and homeowners across continents use Feng Shui practices for building placements and decoration of dwellings and workplaces. Feng Shui practice has some limitations such as conflicting opinions of experts and increased complexity when the dimension of time is taken into consideration. Still, Feng Shui as a practice is growing globally adjusting itself to regional and cultural challenges.

Key words: Feng Shui, social influence, informational, utilitarian, value-expressive

\footnotetext{
* Assistant Professor of Marketing College of Business Butler University(bflorent@butler.edu), Corresponding author

** Assistant Professor of Management College of Business Butler University

*** Assistant Professor of Management Information Systems College of Business Butler University
} 


\section{Introduction}

Feng Shui is an ancient art and science developed over 3,000 years ago in China (Hobson 1994). It is a complex body of knowledge that reveals how to balance the energies of any given space to assure health and good fortune for people inhabiting it (Hobson 1994). Feng Shui became significantly popular in East Asia in places such as Singapore, Malaysia, Hong Kong, Korea, and Taiwan and is practiced at work as well as at home by businesses and by consumers (Hobson 1994; Lu and Jones 2000; Payton 2008; Tsang 2004; Weltman and Hayes 2005; Zetlin 1995). It is rapidly entering Western countries and is used by non-Asian populations (Gunn 1997; Payton 2008; Stimach and Austin 2003).

As more people adopt Feng Shui practices, a marketing opportunity was identified by a Feng Shui expert Lillian Too and her daughter Jennifer Too. They saw an opportunity to establish an on-line and off-line presence to sell and promote Feng Shui artifacts. Lillian Too shares her Feng Shui expertise through her books, a magazine, and her seminars, coupled with a regularly updated web site named World of Feng Shui (www.wofs.com). She is also actively involved in designing and promoting Feng Shui products in a virtual mall named mega-mall and franchised retail stores that exist throughout the world selling these products.
This paper examines the success of Lillian Too's enterprise through the theoretical lenses of social influence. Social influence has three aspects: informational, utilitarian, and valueexpressive. As Feng Shui practices have not been widely examined, particularly using a consumer behavior approach, this paper significantly contributes to the existing body of research in this field by analyzing a business practice using a theoretical conceptualization. The analysis of this case study will reveal how social influence concepts are successfully implemented in a Feng Shui enterprise.

\section{Theoretical Background}

\subsection{Feng Shui}

The history of Feng Shui covers 3,500+ years (Wang 2000) and dates back to before the invention of the magnetic compass. Its origins are in astronomy (Shi 1990). Some current practices can be traced to Neolithic China, (Wang 2000) while others were added later (most notably during the Han, Tang, Song, and Ming dynasties; (Jun and FernandesGonçalves 1998). "Feng" means "wind" and "Shui" means "water" (pronounced fung-shway). In Chinese culture, gentle wind and clear water have always been associated with good harvests and good health, thus "good Feng Shui" came 
to mean good livelihood and fortune, while "bad Feng Shui" came to mean hardship and misfortune.

Feng Shui is based on the Taoist vision and understanding of nature, particularly on the idea that the land is alive and filled with Qi (ch'i) or energy/life force. The ancient Chinese believed that the land's energy (Qi) could either make or break the kingdom, so to speak. The theories of Yin and Yang, as well as the five Feng Shui elements, are some of the basic aspects of a Feng Shui analysis that come from Taoism.

The main tools used in a Feng Shui analysis are the Compass and the $\mathrm{Ba}-\mathrm{Gua}$. The $\mathrm{Ba}^{-}$ Gua is an octagonal grid containing the symbols of the I Ching, the ancient oracle on which Feng Shui is based. Knowing the Ba-Gua of your home will help you understand the connection of specific Feng Shui areas of your home to specific areas of your life. Compasses reflect local geomagnetism, including variations in the electromagnetic fields produced by the Earth and induced currents caused by space weather (Lui et al. 2006).

Polarity is expressed in Feng Shui as Yin and Yang Theory which is equivalent to a bipolar magnetic field. That is, Yang is creating an exertion and Yin is receiving the exertion. The "elements" of Feng Shui (water, wood, fire, earth/soil, metal) are made of Yin and Yang in precise amounts (Greater wood has less Yin than lesser wood, but not as much
Yin as water, and so forth). Earth is a buffer, or equilibrium, achieved when the polarities cancel each other. This explains why Feng Shui is said to be about balance.

The goal of Feng Shui as practiced today is to situate the human-built environment on spots with good Qi. The "perfect spot" is a location and an axis in time. Accordingly, it is believed that some areas are not suitable for human settlement and should be left in their natural state. Feng Shui is related to the very sensible notion that living with rather than against nature benefits both humans and our environment. It is also related to the equally sensible notion that our lives are deeply affected by our physical and emotional environs. If we surround ourselves with symbols of death, contempt, and indifference toward life and nature, with noise and various forms of ugliness, we will corrupt ourselves in the process. If we surround ourselves with beauty, gentleness, kindness, sympathy, music, and with various expressions of the sweetness of life, we ennoble ourselves as well as our environment.

Feng Shui experts/masters, those who understand the five elements and the two types of energy such as Qi and Sha (hard energy, the opposite of Qi) are hired to recommend directions for optimal energy flow inside or outside a home. They can recommend where bathrooms should go, which way doorways should face, where mirrors should hang, which room needs green plants and which one needs red flowers, which 
direction the head of the bed should face, etc. Ancient literature has been used to develop guidelines for practicing Feng Shui. The following methods are examples of these guidelines (Jun and Fernandes-Gonçalves 1998):

- Ba-Gua (relationship of the five phases or wuxing)

- Five phases (wuxing relationships)

- Xuan Kong (time and space methods)

- Xuan Kong Fei Xing (Flying Stars methods of time and directions)

- Xuan Kong Da Gua ("Secret Decree" or 64 gua relationships)

- Xuan Kong Shui Fa (time and space water methods)

- Zi Bai (Purple-White Flying Stars methods)

- Ba Zhai (Eight Mansions)

- San Yuan Dragon Gate Eight Formation

- Major \& Minor Wandering Stars

- San He Luan Dou (24 Mountains, MountainWater relationships)

- San He Shui Fa (water methods)

- Qi Men Dun Jia (Eight Doors and Nine Stars methods)

- Zi wei dou shu (Purple King, 24-star astrology)

In the 1960s, Feng Shui was introduced to the West. Regardless of the country of practice, East or West, businesses typically use Feng Shui to increase sales and boost morale. Homeowners have come to use Feng Shui in an attempt to live happy, prosperous, successful lives. One of the grievances mentioned when the anti-Western Boxer Rebellion erupted a century ago was that Westerners were violating the basic principles of Feng Shui in their construction of railroads and other conspicuous public structures throughout China. At the time, Westerners had little idea of, or interest in, such Chinese traditions. In contrast, since Richard Nixon journeyed to The People's Republic of China in 1972, Feng Shui has become something of an industry in Western countries (Goodall 2001). The Getty Center in Los Angeles on the American West Coast is the best example of 1990s-style Feng Shui influence and theory.

With the opening up of China to the West, Feng Shui became increasingly known and also practiced by Western trading companies to satisfy local business communities, and also to encourage luck in business. From the early 1990s Feng Shui practice has been growing in the North American West Coast, principally in California and British Columbia. Countless architects, landscape designers, restaurant designers, and Hollywood stars have embraced Feng Shui and it has had a strong influence on newer buildings, architects, and designers globally.

Research has begun to develop examining the traditional forms of Feng Shui that are used and taught in Asia. The main areas of research are in areas of landscaping, ecology, and architecture (Chen and Nakama 2004; Chen et al. 1997; Hwangbo 2002; Lau et al. 
2005: Marafa 2003; Park and Yamada 1996; Whang and Lee 2006; Xu 2003; Xu 1998; Zhuang and Corlett 1997). Few studies have addressed Feng Shui practices in the business community. The present research is one of the first to examine Feng Shui practice in the context of consumer behavior theory.

\subsection{Social Influence}

Consumers do not make decisions in isolation. The values, beliefs and opinions of those who surround the consumer affect their decisions. Thus, the consumer behavior, including purchasing and consumption decisions, is subject to social influence. Deutsch and Gerard (1955) distinguished between two types of social influence, informational and normative. Consumer research has separated normative influence into utilitarian and valueexpressive influences (Bearden and Etzel 1982; Park and Lessig 1977). Informational influence is defined as an influence to accept information obtained from another as evidence about reality (Deutsch and Gerard 1955). Utilitarian influence is reflected in individuals' attempts to comply with the expectations of others in order to obtain rewards or avoid sanctions (Park and Lessig 1977). Value-expressive influence happens when individuals use others' values and behaviors as a model for their own attitudes and behaviors (Park and Lessig 1977).

According to Kelman (1961), reference group influence, such as social influence, operates through three separate processes: internalization, compliance and identification. Internalization is a process relevant to informational influence. Informational influence is internalized when it helps solve an individual's problems or when it supports or adds to an individual's beliefs about an aspect of their environment. Information from a credible source (e.g., expert) will most likely lead to internalization (McGuire 1969).

On the other hand, utilitarian influence operates through the process of compliance (Bearden and Etzel 1982; Bearden et al. 1989). Compliance occurs when the individual conforms to the expectations of another in order to receive a reward or avoid a sanction mediated by that other. Identification process has been associated with value-expressive influence. Identification occurs when an individual adopts a behavior or opinion derived from another to satisfy the self-defined relationship to the other, which is beneficial to some portion of the individual's self concept (Brinberg and Plimpton 1986).

Types of information that a consumer is motivated to acquire might differentiate type of social influence on that consumer. When the consumer is motivated to acquire general productrelated knowledge that can be internalized for future purchase/consumption he/she will be more susceptible to informational influence. When the same consumer is motivated to get advice on a specific purchase/consumption of an existing product that renders rewards or prevents sanctions he/she will be more susceptible to 
utilitarian influence.

Product conspicuousness also affects which type of social influence is likely to operate in a consumer behavior context. Some products are perceived as conspicuous, which are "public" and "luxury" (Bearden and Etzel 1982). The consumption of "public" products is more visible than consumption of "private" products, resulting in stronger susceptibility to opinions and approval of important others (Fisher and Price 1992). "Luxury" products are potentially more susceptible to social influence than "necessity" products as they are more exclusive and may draw more attention in the social setting (Bourne 1957; Brinberg and Plimpton 1986). Identification is probably the more dominant process of social influence in relation to consumption/purchase of conspicuous products than compliance or internalization. Thus, consumption or purchase of conspicuous products will most likely be susceptible to value-expressive influence (Lord et al. 2001).

\subsection{Internet Marketing}

The Internet has enabled a new era in marketing. Internet marketing brings customers and organizations together in e-commerce. The amount of information available to customers has readjusted the power balance between businesses and their customers, and Internet marketing is useful in both disseminating information and collecting data for marketing purposes
(Radin and Calkins 2007). Technology makes possible a whole new world of marketing. And E-marketing is taking its place alongside more traditional modes of marketing. The goals of E-marketing include enhancing customer relationships, building product awareness, encouraging customer loyalty, and seeking to acquire future businesses (Art 2006). E-marketing is an exciting opportunity for companies to reach a broader market and to better communicate and service current customers.

The more intense e-marketing usage is connected with a stronger competitive position, and there is a positive relationship between organizational performance and e-marketing utilization (Bernroider 2008). Taking active approaches with e-marketing campaign may help companies keep their brand top-of-mind on the Internet. The following tools could help companies increase sales, site traffic, and site visitor durations; in many cases, marketers must engage in more than one activity to gain the best result: 1. pay-perclick, 2. web site advertising, 3. paid inclusion, 4. e-mail marketing, 5. strategy development, 6. campaign development, 7. message creative development, 8. message content development, 9. list acquisition, and 10. e-mail delivery and tracking (Davis 2005).

Countries and cultures have different approaches on how to use the internet in making purchase decisions. Cultural differences are both material (purchase behavior) and non-material (customs, attitudes and laws; Dilts and Hauser 2006). 
Marketers know that they need to "think global and act local' when trying to extend a brand to new countries and cultures, and the Internet ensures that popular culture and news are generally available to all (Hollis 2009). Therefore, successful e-businesses that strive to grow globally without losing local markets need to identify, understand and integrate local cultural nuances, by developing hybrid multi-channel approaches that use the Internet to enhance preferred local purchase decision-making and behavior patterns (Dilts and Hauser 2006).

Internet marketing have created a new type of client/prospect, one who is forward thinking, technologically literate and demands to be educated before engaging in business's services. Physical distances no longer isolate businesses' clients from competitors inside and outside local markets. There is a tremendous opportunity to reach niche buyers directly with targeted messages on the Internet that cost a fraction of what bigbudget advertising costs. Internet marketing is about delivering value-rich content at just the precise moment that a buyer needs it. Internet content directly contributes to a business's online reputation and demonstrates thought leadership in the marketplace. (Monesson 2008).

As the Internet continues to evolve, users' expectations and behaviors online are transforming. Prospective customers now have the ability to create content online and play a more active role in developing and maintaining relationships with companies; consumers play a greater role in managing their online experiences, therefore, creating engaging and relevant communication is increasingly important (Schwarz 2008). When developing Internet marketing strategies companies should specifically: (a) look for ways to achieve two-way communication, (b) build positive relationships and add value, (c) understand prospective customers, and (d) be open to change (Schwarz, 2008).

A recent study of the survey from consumers in three countries, the United State, India, and Korea revealed that the perception of time pressure are positively related to consumer preference for Internet shopping mode (Lee et al. 2009). In addition, for online marketing, $e^{-}$ service quality has an influence on customer satisfaction and then generates customer loyalty. The relationship between customer satisfaction and loyalty is stronger for customers with high perceived value than low perceived value (Chang et al. 2009). Therefore, in order to have successful Internet marketing companies should focus on more user friendly navigation design as well as improve e-service quality to increase the effectiveness and positive experience of their online customers which will enhance their perceived value.

Professionals in different fields have found that Internet marketing strategy is increasingly important to developing new client relationships and keeping the existing clients' loyal. While varying in focus, such a strategy encompasses several components: (1) a Web site where the 
advisor can promote his or her expertise, (2) electronic media, such as e-newsletters and blogs, for conveying new information of interest to clients, (3) social media networks where the advisor can connect with prospective clients or other professionals, and (4) technological tools to leverage and monitor the effectiveness of marketing techniques. To generate significant Web traffic all components of an online marketing strategy need to be tightly integrated. With regards the Web portal, keeping tabs on what clients are viewing and, when necessary, making improvements will increase business-client readerships and page-views (Hersch 2009).

\section{Case Study Analysis}

\subsection{Research Approach}

World of Feng Shui (WOFS) enterprise was selected as a case study for this paper because (a) it markets Feng Shui products and services using a multi-channel strategy, and (b) it provides rich (e.g., many categories), diverse (e.g., letters, articles), and frequently updated secondary data content. Examples of WOFS secondary data were categorized into the relevant theoretical concepts to illustrate how the concepts are utilized by WOFS' marketing strategies.

\subsection{World of Feng Shui Enterprise}

\subsubsection{Lillian Too's Expertise}

Lillian Too is of Chinese decent and lives in Malaysia. She did her MBA in Harvard University and successfully held several top executive positions. She has established herself as a Feng Shui expert by publishing many books, mostly in English, on this subject. Some examples of her books are: The Complete Illustrated Guide to Feng Shui: How to Apply the Secrets of Chinese Wisdom for Health, Wealth and Happiness (1996), Total Feng Shui: Bring Health, Wealth, and Happiness into Your Life (2004), and Flying Star Feng Shui for Period 8 by Lillian Too (2005). She has also conducted workshops related to Feng Shui (e.g., master practitioner courses in Feng Shui) and regularly participates as a speaker in Feng Shui related global events (e.g., Feng Shui Extravaganza 2009, International Feng Shui Convention 2008). She is featured regularly on the Malaysian radio and TV and owns several Feng Shui retail stores. She also designs many of the Feng Shui products she sells through the Mega-mall website and the retail stores. Thus, her expertise in the field of Feng Shui has been well established over the years.

\subsubsection{WOFS website}

The World of Feng Shui (WOFS) website 
was established by Lillian Too and her daughter Jennifer Too. The website includes mostly articles that provide information on Feng Shui and related subjects (e.g., astrology, Chinese beliefs). The website also includes postings of Q \& A (ask Lillian Too and Aunt Agga), forums, advertisements (e.g., events, courses, and products), information on Feng Shui associates/consultants, and links to the Mega-mall website, Lillian Too's website, and franchised Feng Shui retail stores.

\subsubsection{FSW magazine}

The bi-monthly magazine includes many features similar to those of the WOFS website. It provides Feng Shui information through articles, has Aunt Agga's Q \& A sections, presents advertisements of Feng Shui associates/ consultants, upcoming events, and products that are sold through the Mega-mall and the retail stores. It also includes astrological information and articles on Lillian Too's and other celebrities' lifestyle and homes.

\subsubsection{Mega-mall website}

This website includes Feng Shui products that consumers can buy to enhance their good luck or prevent their bad luck. The Mega-mall sells decorative items, jewelry, and books (e.g., body Feng Shui, horses for success, horoscope allies). The website describes the Feng Shui meaning for each item. For example, for the product named "Carp with I-Ching Coin" the description is:

"The Carp or Dragon Fish symbolizes perseverance because of its legendary valor in swimming against the current. Carp with coin is also symbolized abundance and wealth. Display this auspicious carp anywhere in your home to enjoy abundant good fortune and prosperity luck. For business, place on your work desk to achieve career success" (www.fsmegamall.com).

The website also provides a categorization of products based on Feng Shui aspirations/goals which relate to the Ba-Gua: career, children, education, fame, health, love, mentors, wealth, and symbols of protection. The book section presents Lillian Too's publications and the fine jewelry section showcases jewelry designed by Lillian Too. Another section on the website is called House of Too and it presents various products with an option to get a description of the Feng Shui meaning. The website also has a link to Lillian Too's workshops/courses.

\subsubsection{Franchised retail stores}

The franchised retail stores called World of Feng Shui Boutiques carry Feng Shui products which are similar to those sold on the Megastore website. The greatest number WOFS Boutiques operate in Malaysia (16 stores), several owned by Lillian Too. Many stores are located in 
other East Asia countries (e.g., Japan, Philippines, Indonesia, and Thailand). Stores are also located in North America (Canada and USA), Central America (Guatemala), Europe (e.g., UK, Belgium, and Spain), East Europe (Russia and Ukraine), Australia and New Zealand. Many of the store owners are individuals who have attended Lillian Too's courses/workshops.

\subsubsection{Events, course/workshops, and TV appearances.}

Lillian Too also organizes several events and workshops through the year which help her promote WOFS products and services. Feng Shui Extravaganza is one of them. She travels internationally during the first two months of each year to give Feng Shui updates with respect to that year. Also, she conducts several courses and workshops in Malaysia giving certifications to her graduates for successfully completing the course. The students come from many different countries. For example, in her April 2009 course students came from 27 countries. She is invited to give key note speeches at conferences and conventions (e.g., International Feng Shui Convention in Singapore in November 2008). Finally, she appears on TV regularly sharing her expertise with Malaysians and audiences from other countries. These off-line promotional tools feed into her WOFS enterprise as she can promote many of her products and services through these avenues.

\subsection{Analysis of the Business Components}

The social influence framework is adopted to analyze the success of the WOFS enterprise. The various business components can be associated with the three types of social influence: informational, utilitarian, and value-expressive. Table 1 presents these associations. Both the WOFS website and the FSW magazine address the three components to some extent. Both include articles, Q \& A sections, product promotions, and event promotions. In fact, many of the articles placed regularly on the WOFS website are from past issues of FSW magazine. Offline activities include franchised retail stores, events Lillian Too organizes or being invited to, courses and workshops she conducts regularly, and regular appearance on TV.

The Q \& A sections address the utilitarian influence providing individuals with problemspecific recommendations. The articles are classified as informational influence as they suggest more general Feng Shui practices. However, some articles suggest products that can be purchased via the Mega-mall website or the retail stores. Both outlets (WOFS website and FSW magazine) promote products that can be purchased either at the Mega-mall website or in the franchised retail stores. Thus, the promoted products are classified as value-expressive influence. The magazine however has larger and more colorful pictures of the products explaining their Feng Shui meaning. 
〈Table 1〉 Classification of Business Components into Social Influence Types

\begin{tabular}{|c|c|c|c|}
\hline Business Component & $\begin{array}{c}\text { Utilitarian } \\
\text { (Compliance) }\end{array}$ & $\begin{array}{c}\text { Informational } \\
\text { (Internalization) }\end{array}$ & $\begin{array}{c}\text { Value-expressive } \\
\text { (Identification) }\end{array}$ \\
\hline \multicolumn{4}{|l|}{ WOFS website/ FSW magazine: } \\
\hline $\mathrm{Q} \& \mathrm{~A}$ & + & & \\
\hline Articles & & + & \\
\hline Product Promotions & & & + \\
\hline Event Promotions & & + & \\
\hline Mega-mall website & & & + \\
\hline Franchised retail stores & & & + \\
\hline Events, courses/workshops, and TV & & + & \\
\hline
\end{tabular}

Both the Mega-mall website and the franchised retail stores are classified into value-expressive influence as they mostly sell Feng Shui products. As the business components complement (articles and products) and overlap each other (same articles in FSW magazine and on the WOFS website) they strengthen individuals' susceptibility to Lillian Too's overall social influence. Even so, each type of social influence can be identified distinctly and mapped onto relevant business component/s.

Individuals will be susceptibility to informational influence by a Feng Shui expert if they perceive that the information will help them improve their ability to cope with the environment inside or outside of their home. They can internalize the knowledge presented by Feng Shui experts (e.g., Lillian Too) so they can achieve desired goals (e.g., happiness or good fortune) or prevent unwanted consequences (e.g., illness or bankruptcy). The Feng Shui experts have the knowledge of correct Feng Shui practices. Thus, individuals learn form the experts how to choose Feng Shui practices to achieve their goals.

In the case of WOFS components, articles mostly generate the informational influence of Feng Shui. They (1) provide explanation of definitions, (2) suggest general Feng Shui practices, and/or (3) present visual examples of products, and product placements. Table 2 presents an analysis of an article that has been published in FSW magazine (March/April 2006) and on the WOFS website. The article addresses clarifications regarding definitions (e.g., big vs. small water). Suggestions of correct practices with water are presented (e.g., auspicious directions of placing water features) as well as caution against incorrect practices (e.g., placement of water inside the house). Finally, the article give suggestions of products (e.g., fish) that can probably be found on the Mega-mall 
website and product placements (e.g., place stone-based water feature in water star 8 section) based on each basic element of each direction which is based on $\mathrm{Ba}-\mathrm{Gua}$ and flying star charts. We consider the articles to represent more informational influence as they provide general Feng Shui recommendations that may not be relevant at the moment to the readers. However, if they are internalized they can be practiced later one when the appropriate situation occurs. For example, an individual may not be able to place a water fountain in her current apartment but might consider it as a present for a friend or might later place one when she moves to a different apartment.

The off-line activities such as events, courses/ workshops, and TV shows are also informational in nature (Table 3). They provide mostly

〈Table 2〉 Example: Analysis of the Article "Clever Ways with Water"

\begin{tabular}{l}
\hline Content \\
"Firstly I want to make a difference between big water and \\
small water" \\
"Secondly I want to make a difference between a flow of \\
water and an accumulation of water" \\
"Thirdly you must differentiate between hole-in-the-ground \\
water, and elevated water." \\
"This kind of water is best when located in the North \\
direction of your garden." \\
"Water accumulating in the East sector of your house or \\
garden is also very auspicious for 2006." \\
"Note that a hole in the ground water feature should never \\
be dug inside the house." \\
"Do not forget that you should never have a hole-in-the- \\
ground water on the right hand side of your main door \\
(inside looking out)." \\
"Keeping Fish: \\
... What kind of fish you keep is a matter of personal \\
preference, but I have found the arowana, goldfish and carp \\
to be excellent enhancers of success and wealth luck." \\
"Choose the best water feature to suit where you're gonna \\
place it... \\
Stone-Based Water Feature \\
Water features like these are ideal for enhancing water star \\
8 sectors that also have the mountain star $8 . "$
\end{tabular}


predictions and suggestions for protections from bad luck and enhancements of good luck for present or upcoming year as well for different
Chinese zodiac signs. The Feng Shui extravaganza event also discusses protections and enhancements for different industries. These off-line activities

〈Table 3〉 Examples of Events, Courses/Workshops, TV Appearances

\begin{tabular}{|c|c|c|c|}
\hline Type of Activity & Purpose/Description & Generated Information & $\begin{array}{l}\text { Promoted Products } \\
\text { and Services }\end{array}$ \\
\hline $\begin{array}{l}\text { Master Practitioner } \\
\text { Course in Feng Shui }\end{array}$ & $\begin{array}{l}\text { Intensive 5-day course on } \\
\text { the fundamentals of Feng } \\
\text { Shui practice. }\end{array}$ & $\begin{array}{l}\text { - Incorporates all compass } \\
\text { and landscape formulas. } \\
\text { - Curriculum includes } \\
\text { active discussions, } \\
\text { practical work and onsite } \\
\text { assessments. }\end{array}$ & $\begin{array}{l}\text { - Students are taught to } \\
\text { use the Luo Pan. } \\
\text { - Many of this course } \\
\text { graduates have become } \\
\text { consultants or WOFS } \\
\text { store owners in their } \\
\text { home countries. }\end{array}$ \\
\hline $\begin{array}{l}\text { Feng Shui } \\
\text { Extravaganza }\end{array}$ & $\begin{array}{l}\text { Feng Shui updates of } \\
\text { each year }\end{array}$ & $\begin{array}{l}\text { - Prediction for the } \\
\text { upcoming year to } \\
\text { different Chinese zodiac } \\
\text { signs and industries. } \\
\text { - Suggested protections } \\
\text { and enhancements for the } \\
\text { upcoming year. }\end{array}$ & $\begin{array}{l}\text { - Performed in different } \\
\text { countries such as USA } \\
\text { (Hawaii), Netherlands } \\
\text { (Amsterdam), UK } \\
\text { (London), Hong Kong. } \\
\text { - Hosted by WOFS retail } \\
\text { store owners (graduates } \\
\text { of Lillian Too's courses) } \\
\text { - WOFS products are } \\
\text { promoted for protection } \\
\text { from bad luck and } \\
\text { enhancement of good luck }\end{array}$ \\
\hline $\begin{array}{l}\text { Lillian Too on TV } \\
\text { (e.g., CNN, } \\
\text { Hallmark) }\end{array}$ & Sharing zodiac tips & $\begin{array}{l}\text { - Sharing what remedies } \\
\text { (products) should be } \\
\text { applied to different } \\
\text { Chinese zodiac signs. An } \\
\text { example for a Dragon (in } \\
\text { 2009) is to wear an } \\
\text { empowerment ring or } \\
\text { mantra ring as protection } \\
\text { from low spirit essence. }\end{array}$ & $\begin{array}{l}\text { - Products that are sold in } \\
\text { the WOFS mega mall are } \\
\text { promoted. }\end{array}$ \\
\hline $\begin{array}{l}\text { International Feng } \\
\text { Shui Convention in } \\
\text { Singapore }\end{array}$ & $\begin{array}{l}\text { Discussion of Feng Shui } \\
\text { practices by master } \\
\text { practitioners including } \\
\text { Lillian Too who was the } \\
\text { key note speaker. }\end{array}$ & $\begin{array}{l}\text { - Popularizing the } \\
\text { understanding and use of } \\
\text { Feng Shui in different } \\
\text { industries. }\end{array}$ & $\begin{array}{l}\text { - Promoting WOFS } \\
\text { enterprise. }\end{array}$ \\
\hline
\end{tabular}


that feature Lillian Too promote her products and WOFS enterprise. For example, the Feng Shui extravaganza events are organized many times by the franchised retail stores which sell WOFS products.

Utilitarian influence involves mostly compliance to behavior that renders rewards or prevents punishments (Brinberg and Plimpton 1986; Park and Lessig 1977). In relation to Feng Shui, the utilitarian influence is based on socially held beliefs that Feng Shui practices can enhance good luck (reward) and/or bad luck (sanction). The Q \& A sections/postings can be considered representative of the utilitarian influence as they give experts (Lillian Too and Aunt Agga) the opportunity to provide individuals with problem-specific recommendations.

〈Table 4〉 presents an analysis of one letter with a corresponding response from Lillian Too that illustrates how the reward/sanction mechanism plays a significant part in the letter and its response increasing the individual's compliance to utilitarian influence. The letter revolves around the bad luck of a woman's husband that she believes is due to the placement of the kitchen in her house. Thus, the utilitarian sanction is already present in the house as she built it with no Feng Shui knowledge. After reading Lillian Too's book on the Ox year sign (internalized informational influence) she realizes that the kitchen suppresses her husband's luck (sanction) and she does not want to make significant changes to the house or move.
Lillian Too gives specific remedies to this problem thus providing ways to suppress bad luck and increase good luck, both of which can be considered a reward for complying with her recommendations. The interplay between the sanctions (e.g., yellows in the $\mathrm{NE}$ ) and the rewards (e.g., sheng chi sleeping directions) strengthen the compliance to Lillian Too's recommendations. Also, Lillian Too strengthens her utilitarian influence by stating that to get the desired rewards, the "cures" need to be implemented and that her suggestion with the brass fan has helped other people.

Several of Lillian Too's recommendations relate to placements of products that she sells in her Mega-mall and retail stores (e.g., mantra ring, five-element pagoda) which reinforce the value-expressive influence of these stores. Value-expressive influence is present in Feng Shui practices. It involves placement of objects (e.g., water fountain) in different parts of the house (e.g., east) that is visible (conspicuous) to other people (e.g., friends, relatives). Usually, the visitors have some knowledge of Feng Shui practice and may even be engaged in practicing Feng Shui themselves.

As value-expressive influence produces enhancement of self-concept through the process of identification (Brinberg and Plimpton 1986), purchase and consumption of the Feng Shui products is most probably susceptible to this type of influence. 〈Table 5〉 analyzes a few products that tap into different aspirations/goals in terms of conspicuousness.

\section{4 한국마케팅저널 제11권 제2호 2009년 7월}


〈Table 4〉 Example: Analysis of a Q \& A Posting from ${ }^{\text {2nd }}-3^{\text {rd }}$ of June 2007

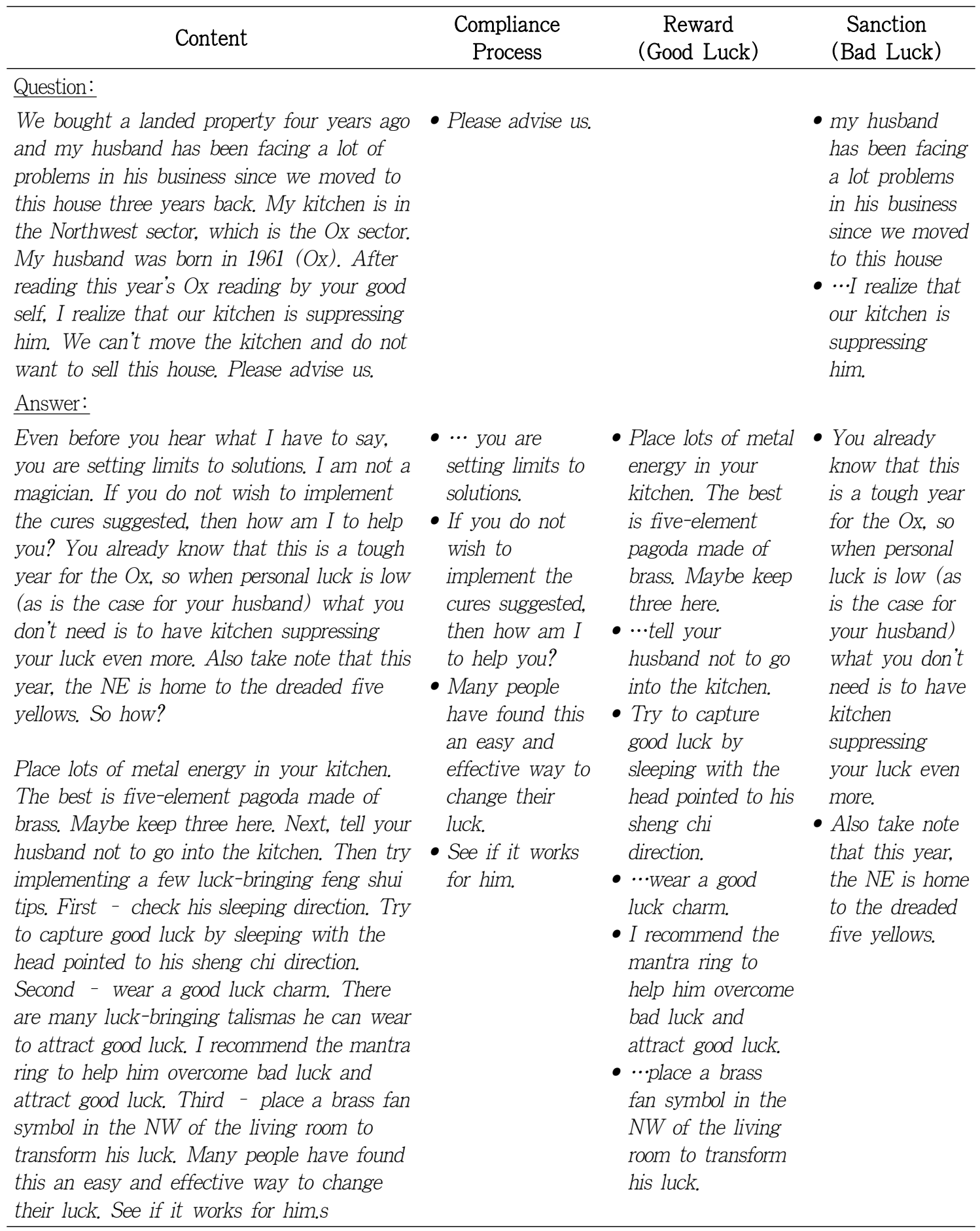


The products presented in 〈Table 5$\rangle$ were chosen from the Mega-mall website. The product description, which includes the meaning and correct practice, addresses the aspirations and goals in terms of enhancing rewards (e.g., instant success) or diminishing sanctions (e.g., protect against falling ill). In this way the value-expressive influence is strongly related to the utilitarian influence. Other researchers have also found inter-relatedness between the two

〈Table 5〉 Example: Analysis of Products and their Meanings Posted on the Mega-mall Website

\begin{tabular}{|c|c|c|c|}
\hline Product & Meaning/Practice & Aspirations \& Goals & Conspicuousness \\
\hline Fly On Horse & $\begin{array}{l}\text { The Fly sitting on a horse carries the } \\
\text { meaning of "mah shiong yeng" - instant } \\
\text { success. Display this horse on your work } \\
\text { desk or at the south corner of your living } \\
\text { room to help you to overcome all obstacles } \\
\text { and bring you success in everything that } \\
\text { you do. Make sure that you display this } \\
\text { horse when you plan to ask your boss for a } \\
\text { raise. }\end{array}$ & $\begin{array}{l}\text { Career: } \\
\text { - Instant success } \\
\text { - } \cdots \text { to help you to } \\
\text { overcome all obstacles } \\
\text { and bring you success } \\
\text { in everything that you } \\
\text { do. } \\
\text { - } \cdots \text { ask your boss for a } \\
\text { raise }\end{array}$ & $\begin{array}{l}\text { - Display this } \\
\text { horse on your } \\
\text { work desk or at } \\
\text { the south corner } \\
\text { of your living } \\
\text { room... }\end{array}$ \\
\hline $\begin{array}{l}\text { Wu Lou with } 8 \\
\text { Immortal Object }\end{array}$ & $\begin{array}{l}\text { The } 8 \text { immortal shown surrounding the } \\
\text { Wu Luo brings good health and longevity } \\
\text { luck. Display this health gourd in the } \\
\text { North West of the home in } 2008 \text { to protect } \\
\text { against falling ill. }\end{array}$ & $\begin{array}{l}\text { Health: } \\
\text { - } \cdots \text { good health and } \\
\text { longevity luck } \\
\text { - } \cdots \text { to protect against } \\
\text { falling ill. }\end{array}$ & $\begin{array}{l}\text { - Display this } \\
\text { health gourd in } \\
\text { the North West } \\
\text { of the home in } \\
2008 \cdots\end{array}$ \\
\hline 3 Legged Pikan & $\begin{array}{l}\text { This is the one of the essential wealth } \\
\text { enhancer for year 2008. This 3-legged Pi } \\
\text { Kan attracts wealth luck at your entrance. } \\
\text { You need to place one at each side. One of } \\
\text { the legs is taking up to invite the wealth } \\
\text { luck to your house. This is the yearly } \\
\text { protection amulet that everyone MUST } \\
\text { carry it with you at all times. }\end{array}$ & $\begin{array}{l}\text { Wealth: } \\
\text { - This is the one of the } \\
\text { essential wealth } \\
\text { enhancer for year } 2008 \text {. } \\
\text { - ...attracts wealth luck } \\
\text { at your entrance. } \\
\text { - ...invite the wealth } \\
\text { luck to your house. }\end{array}$ & $\begin{array}{l}\text { - You need to } \\
\text { place one at } \\
\text { each side [of the } \\
\text { entrance]. }\end{array}$ \\
\hline Bejeweled Heart & $\begin{array}{l}\text { The heart is a special symbolic shape, for } \\
\text { it reminds us of the power of love. To give } \\
\text { someone a heart shaped item is a way of } \\
\text { saying that your own heart is open to him } \\
\text { or her. It teaches us to love ourselves, thus } \\
\text { opening us up to Universal love. It assists } \\
\text { in healing emotional wounds and helps to } \\
\text { overcome grief. Place it in the Southwest } \\
\text { is a sure-fire way to attract marriage luck } \\
\text { into your life. }\end{array}$ & $\begin{array}{l}\text { Love: } \\
\text { - ..love ourselves, thus } \\
\text { opening us up to } \\
\text { Universal love. } \\
\text { - It assists in healing } \\
\text { emotional wounds and } \\
\text { helps to overcome } \\
\text { grief. } \\
\text { - ...to attract marriage } \\
\text { luck into your life. }\end{array}$ & $\begin{array}{l}\text { - To give someone } \\
\text { a heart shaped } \\
\text { item } \cdots \\
\text { - Place it in the } \\
\text { Southwest }\end{array}$ \\
\hline
\end{tabular}


(Brinberg and Plimpton 1986; Lord et al. 2001). The product description also taps into the conspicuous aspect of the value-expressive influence. The recommendations include placing products in different parts of the home (e.g., North West, work desk) and/or giving them as a gift which makes it highly probable that they will be visible to others.

\section{Discussion}

This case study analysis demonstrates how the three types of social influence are used in marketing Feng Shui to mostly Asian populations. The growing interest in Feng Shui in the West will contribute to the success of the WOFS enterprise as they increase their hold on this niche market. They have the first mover advantage and have well established ties with suppliers, designers, and franchised retail channels building brand equity that transcends global barriers.

Several limitations should be noted with respect to marketing Feng Shui. One problem is that there are many different approaches and experts of Feng Shui, who may give opposite recommendations to the same problem creating confusion and mistrust among the target population. For example, some experts may recommend a water pool on the roof of a building for protection (Hobson 1994) while others will argue that a pool on a roof of a building brings bad luck drowning the fortune of the company (www.wofs.com). Another problem is that Feng Shui accounts for only one third of luck in general, and this third is called earth luck. The other two thirds are heaven luck and man made luck. Thus, when things go wrong, Feng Shui may not be able to prevent the bad luck. A third problem is that flying star Feng Shui requires constant modification of object placement which complicates the practice of Feng Shui.

Still, as the Asian market becomes more central to the global economy, Feng Shui has the opportunity to flourish, be more widely accepted by non-Asian consumers and business people, and be practiced in more continents and industries. Businesses, especially in Asian countries, successfully implement Feng Shui practices. The hospitality industry is one such example (Hobson 1994). Hotels apply Feng Shui practices in many ways. Choosing a location or making physical modification to a building need Feng Shui consultation. Exterior (e.g., windows and entrances) and interior designs (e.g., placement of rooms and stairways) need to comply with Feng Shui practices. The Feng Shui beliefs of a hotel's customers and employees need to be addressed properly through a marketing strategy and organizational communication.

The use of Feng Shui principles is not limited to Asian countries; it is now increasingly popular in Western countries as well. For example, contemporary Western Feng Shui is 
the modern version of traditional Feng Shui. It is a very accessible and flexible approach that is better suited to a Western audience and can be commercialized for consumption by Westerners. In particular, Feng Shui architecture is being used more in Western buildings. Corporations such as Mercedes Benz and Hewlett Packard have been consulting Feng Shui experts. Today, architects, designers, and homeowners in the East and West alike use Feng Shui practices for placement of buildings and decorating dwellings and workplaces. Thus, WOFS enterprise can target not only consumers but also business executives, in Asia and in the West, increasing its opportunities for global growth.

〈received: 2009. 01. 14〉 〈accepted: 2009. 06. 03〉

\section{References}

Art, M. M. (2006), "Reshaping Marketing With an e," LIMRA's MarketFacts Quarterly, 25 (4), 36-42.

Bearden, William O. and Michael J. Etzel (1982), "Reference Group Influence on Product and Brand Decisions," Journal of Consumer Research, 9 (September), 183-94.

Bearden, William O., Richard G. Netemeyer, and Jesse E. Teel (1989), "Measurement of Consumer Susceptibility to Interpersonal Influence," Journal of Consumer Research,
15 (4), 473-81.

Bernroider, E. W. (2008), "E-marketing Utilization, Endogenous Situation and Organizational Performance in Small Austrian Software Businesses," International Journal of Internet Marketing \& Advertising, 4 (2/3), 262.

Bourne, Francis S. (1957), Group Influence in Marketing and Public Relations, Basil, Switzerland: UNESCO.

Brinberg, David and Linda Plimpton (1986), "Self-Monitoring and Product Conspicuousness on Reference Group Influence," Advances in Consumer Research, 13, 297-300.

Chang, Hsin Hsin, Yao-Hua Wang, and WenYing Yang (2009), "The Impact of e-Service Quality, Customer Satisfaction and Loyalty on e-Marketing: Moderating Effect of Perceived Value," Total Quality Management \& Business Excellence, 20 (4), 423-43. Chen, B. X. and Y. Nakama (2004), "A Summary of Research History on Chinese Feng-Shui and Application of Feng-Shui Principles to Environmental Issues," Kyusyu Journal of Forest Research, 57, 297-301.

Chen, Qigao, Ya Feng, and Gonglu Wang (1997), "Healthy Buildings Have Existed in China Since Ancient Times," Indoor and Built Environment, 6 (3), 179-87.

Davis, Jonathan A. (2005), "Proper e-Marketing Bolsters Strategy," Marketing News, 39 (18), 22.

Deutsch, M. and H. B. Gerard (1955), “A 
Study of Normative and Informational Social Influences upon Individual Judgment," Journal of Abnormal and Social Psychology, 51, 629-36.

Dilts, J. and W. J. Hauser (2006), “A Hybrid Multichannel Approach to Internet Marketing: Tthink Globally, Act Locally," International Journal of Internet Marketing \& Advertising, 3 (2), 107.

Fisher, Robert J. and Linda L. Price (1992), "An Investigation into the Social Context of Early Adoption Behavior," Journal of Consumer Research, 19 (December), 477-86. Goodall, H. L., Jr. (2001), “Writing the American Ineffable, or the Mystery and Practice of Feng Shui in Everyday Life," Qualitative Inquiry, 7 (1), 3-20.

Gunn, Eileen P. (1997), "You Say Your Office Has Negative Energy? Try Feng Shui!" Fortune, 136 (6), 64.

Hersch, W. S. (2009), "Using Online Tools To Take Your Practice To The Next Level," National Underwriter. Life \& Health, 113 (4), 19-31.

Hobson, Perry J. S. (1994), "Feng Shui: Its Impacts on the Asian Hospitality Industry," International Journal of Contemporary Hospitality Management, 6 (6), 21-26.

Hollis, Nigel (2009), "Rethinking Globalization," Marketing Research, 21 (1), 12-18.

Hwangbo, A. B. (2002), "An Alternative Tradition in Architecture: Conceptions in Feng Shui and Its Continuous Tradition," Journal of Architectural and Planning Research, 19 (2), 110-30.

Jun, Cheng Jian and Adriana Fernandes-Gonçalves (1998), Chinese Feng Shui Compass: Step by Step Guide, Jiangxi Science and Technology Publishing.

Kelman, Herbert C. (1961), "Processes of Opinion Change," Public Opinion Quarterly, 25 (Spring), 57-78.

Lau, Stephen Siu-Yiu, Renato Garcia, YingQing Ou, Man-Mo Kwok, Ying Zhang, Shao Jie Shen, and Hitomi Namba (2005), "Sustainable Design in Its Simplest Form: Lessons from the Living Villages of Fujian Rammed Earth Houses" Structural Survey, 23 (5), 371-85.

Lee, Dongdae, Audhesh K. Paswan, Gopala Ganesh, and M. J. Xavier (2009), "Outshopping Through the Internet: A Multicountry Investigation," Journal of Global Marketing, 22 (1), 53-66.

Lord, Kenneth R., Myung-Soo Lee, and Peggy Choong (2001), "Differences in Normative and Informative Social Influence," Advances in Consumer Research, 28, 280-85.

$\mathrm{Lu}, \mathrm{Su}-\mathrm{Ju}$ and Peter B. Jones (2000), "House Design by Surname in Feng Shui," Journal of Architecture, 5 (4), 355-67.

Lui, A.T.Y., Y. Zheng, Y. Zhang, H. Rème, M. W. Dunlop, G. Gustafsson, S.B. Mende, C. Mouikis, and L.M. Kistler (2006), "Cluster Observation of Plasma Flow Reversal in the Magnetotail During a Substorm," Annales 
Geophysicae, 24 (7), 2005-13.

Marafa, L. M. (2003), "Integrating Natural and Cultural Heritage: the Advantage of Feng Shui landscape Resources," International Journal of Heritage Studies, 9(4), 307-24.

McGuire, W. J. (1969), The Nature of Attitudes and Attitude Change (2nd ed.), Reading, MA: Addison-Wesley.

Monesson, Eileen. P. (2008), “The E-Marketing Revolution," CPA Practice Management Forum, 4 (8), 5-10.

Park, C. P. and Furukawa N. Yamada (1996), "A Study on the Spatial Composition of Folk Houses and Village in Taiwan for the Geomancy (Feng-Shui)," Journal of Architecture Institute of Korea, 12 (9), 129-40.

Park, C. Whan and Parker V. Lessig (1977), "Students and Housewives: Differences in Susceptibility to Reference Group Influences," Journal of Consumer Research, 4 (September), 102-10.

Payton, Scott (2008), "The Yin Crowd," Financial Management, January, 20-24.

Radin, Tara. J. and Martin Calkins (2007), "New Challenges to Old Problems: Building Trust In E-marketing," Business \& Society Review, 112 (1), 73-98.

Schwarz, E. A. G. (2008), "Building Relationships Through e-Marketing," LIMRA's MarketFacts Quarterly, 27 (2), 52-58.

Shi, Feng (1990), "Zhongguo zhaoqi xingxiangtu yanjiu," Zhiran kexueshi yanjiu, 2.

Stimach, Janet and Katie Austin (2003), "Go
With the Flow," Journal of Property Management, 68 (6), 28.

Tsang, Eric W. K. (2004), "Toward a Scientific Inquiry into Superstitious Business Decision-Making," Organization Studies 25 (6), 923-46.

Wang, Aihe (2000), Cosmology and Political Culture in Early China, Cambridge University Press.

Weltman, Barbara and Michael Hayes (2005), "Feng Shui for Beginners," Journal of Accountancy, 200 (6), 36-39.

Whang, Bo-Chul and Myung-Woo Lee (2006), "Landscape Ecology Planning Principles in Korean Feng-Shui, Bi-bo Woodlands and Ponds," Journal of Landscape and Ecological Engineering, 2 (2), 147-62.

Xu, Jun (2003), A Framework for Site Analysis with Emphasis on Feng Shui and Contemporary Environmental Design Principles Blacksburg, VA: University Libraries, Virginia Polytechnic Institute and State University. Xu, P. (1998), "Feng-Shui Models Structured Traditional Beijing Courtyard Houses," Journal of Architectural and Planning Research, 15 (4), 271-82.

Zetlin, Minda (1995), "Feng Shui: Smart Business or Superstition?" Management Review, 84, 26-27.

Zhuang, Xue Ying and Richard T. Corlett (1997), "Forest and Forest Succession in Hong Kong, China," Journal of Tropical Ecology, 13 (6), 857. 